\title{
Ortak Aklın Devre Dışı Kaldığı Grup Düşünme İçin Önleyici Teknikler: Son Bulgular Işı̆̆gnda Değerlendirme
}

\author{
Prof. Dr. Hamit COŞKUN* \\ Abant İzzet Baysal Üniversitesi, Fen Edebiyat Fakültesi, Psikoloji Bölümü, Bolu / Türkiye \\ Psk. Gamze UYKUCU ARMUTCUOĞLU \\ Bartın Ceza İnfaz Kurumu, Bartın / Türkiye
}

\begin{abstract}
Özet
Bu incelemede grup kararlarında çoğu kez gözlenen grup düşünme konusunda araştırmalara odaklanılmaktadır. Bu gruplar, alternatif düşünceleri göz ardı etmekte ve kendi düşüncelerini değerlendirme veya eleştirmekten kaçınmaktadır. Grup düşünme, gruplarda grup liderinin veya dış ortamın baskı yaptığı, alternatif düşüncelerin göz ardı edildiği ve grup kaynaşmasının veya sargınlığının yüksek olduğu durumlarda gözlenmektedir. Grup düşünme sendromu, grup karar verme aşamasında verilen kararların kalitesini ve verimliliğini olumsuz yönde etkilemektedir. Grup düşünmenin başarısızlığını önleyen bir teknik olan şeytanın avukatı tekniği grup içinde sunulan önerilere alternatif öneri getirme temelli bir yaklaşımdır (Janis, 1972). Bu çalışmada,

* Sorumlu Yazar. Tel: +9053556458 $\quad$ E-posta: hamitcoskun2000@ gmail.com

(C) 2014 Kalem Eğitim ve Sağlık Hizmetleri Vakfı. Bütün Hakları Saklıdır. ISSN: 2146-5606
\end{abstract}


şeytanın avukatı tekniği son yıllarda grup karar verme literatüründe araştırmalarla incelenmiş ve alternatif yöntemlerle birlikte değerlendirilerek ilgili literatür ışığında tartışılmıştır.

Anahtar Kelimeler: Grup düşünme; Şeytanın avukatı; Karar verme.

\title{
Prevention Techniques for The Groupthink Collective Consciousness: An Assessment in Lights of Recent Evidence
}

\begin{abstract}
This review focuses on the recent studies on groupthink phenomena which often occur in group decision making. These groups tend to ignore alternative ideas and not to criticize or to evaluate their ideas. The antecedents of this phenomenon are the strong pressure by either group leader or outside event, ignorance of alternative ideas, and high group cohesion. Groupthink symptom leads to low quality of decisions and productivity in decision making groups. A preventive technique, devil's advocacy, has been suggested to increase alternative ideas to those suggested in decision making groups (Janis, 1972). This review highlights some recent experiments about the effectiveness of devil's advocacy in the literature and provides a broad review including some comparisons between devil's advocacy and other techniques.
\end{abstract}

Keywords: Groupthink; Devil's advocacy; Decision making.

\section{Extended Summary}

Groups that experience groupthink phenomena tend to ignore alternative ideas and avoid evaluating their ideas. The antecedents of this phenomenon are the strong pressure by either group leader or outside event, ignorance of alternative ideas, and high group cohesion. Groupthink symptom leads to low quality of decisions and productivity in decision making groups. Human history in 20th century witnesses 
some outcomes of this thinking in some countries including USA and Turkey.

Some explanations have been developed why groupthink occurs in decision making groups. Strong argument explanation proposes that group members are affected by strong arguments versus weak arguments and thereby they take extreme positions along with these arguments (Burnstein and Vinokur, 1973). Social comparison explanation suggests that group members seek similarity since they tend to compare their ideas with others. Such similarity generates some level of pressure on group members to comply with the group norms.

A preventive technique, devil's advocacy, has been suggested to increase alternative ideas to those suggested in decision making groups (Janis, 1972). There have been some benefits for using this technique in decision making groups. This may lead groups to avoid wrong decisions (Cosier and Schwenk, 1990) and to make effective decisions (Mason and Mitroff, 1981). Devil's advocator is especially beneficial at the onset of group session since it increases the possibility of reconsideration of issues at hand (Janis, 1972). By providing some recommendations it also prevents some detrimental criticisms and complaints since they often lead to a low quality of decisions (Valacich and Schwenk, 1995a).

This review highlights some recent experiments about the effectiveness of devil's advocacy in the literature and provides a broad review including some comparison between devil's advocacy and other 
techniques. The findings of these experiments show that in comparison with dissent technique, devil's advocacy has beneficial effects especially when it is perceived as a reliable in a constructive argument and when the number of it is more than one. Devil's advocacy also leads to a high quality of decisions in planning, rapport and role playing than dialectic inquiry. In addition, it is more effective when devil is advocator is perceived as a leader or an expert than it is not. We propose that this technique can be further more effective in situations when devil is advocator is considered to be an in-group member than an out-group member. Finally, brainstorming prior to decision making can be beneficial for preventing groupthink phenomena. This last suggestion, however, is required for the future studies.

\section{Giriş}

Gruplarda değişik görüşlerin alınması ve ortak kararın veya aklın ortaya çıkması arzulanan bir özelliktir. Ancak bu konuda yapılan araştırmalar grup üyelerinin “ortak aklı” ortaya çıkarmada çoğu kez başarısız olduğuna işaret etmektedir. Bu makalede, grup üyelerinin grup içinde davranışlarının nasıl değiştiği ve hangi durumlarda "grup düşünme" sendromu yaşadıkları üzerinde durulacaktır. Ayrıca, gruplarda karar vermenin daha etkili olması (başka bir ifadeyle "grup düşünmenin" azalması veya "ortak aklın” ortaya çıkması) için önerilen “şeytanın avukatı rolü” ve literatürde sunulan diğer teknikler son zamanlarda yapılan araştırmalar ışığında değerlendirilecektir.

Bireyler tek başına oldukları durumlarda gerçek veya doğru bilgiyi aramakta ve tercihleri bu yönde kullanmaktadırlar. Bununla bir- 
likte çoğu kez tek başına karar vermek zor bir durumdur. Farklı görüşlerin farkına varma veya bu görüşlere maruz kalma, bireylerin vereceği kararların doğru veya isabetli olmasını artırmaktadır. Ancak gruplardaki bireyler, yanlış olsa bile grup kararına uyma davranışı göstermektedir (Asch, 1952b). Bu durum, genelde grup içerisinde tutarlılık, dayanışma ve 'görüşbirliğgi' veya uzlaşma sağlama çabası gösteren küçük ve dışa kapalı gruplarda daha fazla gözlenmektedir. "Grup düşünme" (groupthink) grup üyelerinin gerçekleri göz ardı etmesi ve alternatif düşüncelere dirençli veya kapalı olmasını ifade etmektedir (Janis, 1972). Bu şekilde düşünme biçimi çoğu kez başarısız veya ölümcül sonuçlara yol açmaktadır. Yakın tarihte 1960 yılında A.B.D. nin Küba' da yaklaşık 1000 askerinin ölmesi ve 1000'nin tutsak olması, Vietnam'da yaşanan yenilgi, uzay mekiği Challenger' in kalkıştan sonra infilak etmesi bu tür düşünmenin sonucudur. Yine yakın tarihimizde 1974 yılında Kıbrıs Barış Harekatı'nda iki savaş gemimizi batırmamız ve demokrasi hayatımızda burada sayılamayacak kadar çok sayıda siyasi yanlışlar grup düşünmenin bir sonucudur. Grup düşünme sonucu yanlış kararların çıkmasına yol açan grup içi bazı koşullar mevcuttur. Bunlar:

a. Kişilerin inanmadıkları halde grup kararına uyması,

b. Yüksek grup birlikteliğinin varlığı,

c. Dış dünyaya kapalı bir grup,

d. Liderin yönlendirmeleri,

e. Grup üyelerinin ideoloji, 1 rk vb açısından birbirine benzerliği (Janis, 1972). 
Grup düşünmenin, gruplarda karar alma sürecini olumsuz etkilediği ve alınan kararların kalitesini azalttığ 1 tespit edilmiştir (Aldag ve Fuller, 1993).

\section{Grup Düşünmeyi Açıklayan Yaklaşımlar}

$\mathrm{Bu}$ konuda üzerinde durulması gereken nokta, neden grup üyelerinin bütününün kararlarında aynı yönde hareket ettikleri veya kutuplaştıklarıdır. Grup düşünmeye neden olan grup kutuplaşması, “sosyal karşılaştırma süreçleri” ve "ikna edici görüş” ile açıklanmaktadır (Myers ve Lamm, 1976). "İkna edici görüş” yaklaşımına göre grup üyelerinin başlangıçta farklı mevcut görüşleri olsa da grup üyesi görüşme esnasında yeni ve geçerli bir görüş duyduğunda yeni görüşlerle daha ikna olmuş ve daha uçlarda biri haline gelebilir. İkna edici görüş, bireylerin grup içinde yeni ve ikna edici argümanlar veya savlar ortaya atması sonrasında ortaya çıkar (Burnstein ve Vinokur, 1973). Başka bir deyişle grup içinde ortaya atılan görüşler veya tezler ne kadar ikna edeci olursa, grup üyeleri bu görüşleri daha zayıf olanlara göre dikkate alacaklardır. Hem dikkat çekici, yeni hem de gündeme veya ortama uygun olmasından (ya da tek çare olmasından) dolayı bu görüşler grup üyelerini daha fazla etkilemektedir. Liderin bu tür görüşü desteklemesi durumunda etki daha fazla artmaktadır.

“Sosyal karşılaştırma açıklaması”na göre ise kişiler grup tartışması başlangıcında fikrini söylemezler ve grup tartışması hakkında bilgi sahibi olduktan ve kendi fikirleri ile karşılaştırma yaptıktan sonra fikrini söylerler. Çünkü kişiler, diğer grup üyelerinden çok farklı olmak istemezler. Bu açıklamaya göre, grup içinde üyelerin birbirine benze- 
mesi durumu sosyal karşılaştırmadan dolayı artmakta ve ortaya çıkan bu durum zamanla grup içinde bir norm olmaktadır. Bu "benzer olma normu”, grup üyeleri üzerinde bir baskı oluşturmaktadır. Bu nedenle grup üyeleri, çoğunluğun görüşüne daha fazla uymakta ve tek başına farklı bir görüşü ifade etmekten çekinmektedir.

\section{Grup Düşünmeyi Önleme Tekniği Olan Şeytanın Avukatının Gruplarda Faydaları Konusunda Öneriler}

Grupların düşünce üretme ve karar verme görevleri esnasında "grup düşünme" sendromu birçok hatalı sonuca ya da yanlılığa neden olmaktadır. Bu duruma önlem olarak "şeytanın avukatı" tekniği önerilmektedir (Janis, 1982). Şeytanın avukatı tekniği, ilk olarak kurumsal stratejik karar verme ve karmaşık problemlerin çözümünde kolaylaştırıcı olarak geliştirilmiştir (De Dreu ve Van de Vliert, 1997; Valacich ve Schwenk, 1995b). Bu teknikte gruptaki bir ya da birden fazla kişi, karar alma sürecinde diğer grup üyelerinin düşüncelerine eleştiriler getirmekte ve alternatif düşünceler sunmaktadır (Robbins, 1997).

$\mathrm{Bu}$ tekniğin kullanılmasının bir takım faydaları bulunmaktadır. Birincisi, grupların hatalı düşünmekten kaçınmalarına yardımcı olmaktadır (Cosier ve Schwenk, 1990). Şeytanın avukatı rolüne sahip bireylerden yoksun olan gruplar daha fazla "grup düşünme" durumu yaşamaktadır. İkincisi bu teknik grup kararlarının doğruluğunu veya kalitesini artırmaktadır. Bu tür role sahip olan gruplarda bulunan üyelerin daha geçerli ve değerli fikirleri ortaya çıkarma olasılığı artmaktadır (Mason ve Mitroff, 1981). Üçüncüsü, şeytanın avukatı, grup karar verme sürecinin erken aşamalarında devreye girerse, üyelerinin 
konu üzerinde yeniden düşünmelerini sağlamaktadır (Janis, 1972). Dördüncüsü, şeytanın avukatı, durum hakkında tavsiyeler sunarak olumsuz eleştiri ve şikâyet şeklindeki eleştirilerin önüne geçebilir. Çünkü olumsuz eleştirinin daha düşük sayıda ve kalitede çözüm önerisine yol açtığı bulunmuştur (Valacich ve Schwenk, 1995a).

\section{Şeytanın Avukatı Rolünün Nasıl Verilmesi Gerektiği Konusunda Öneriler}

$\mathrm{Bu}$ önerileri inceleyen kişiler bu rolü bizim kültürümüzde vermenin zor ve hatta imkânsız olduğunu düşünebilirler. Bu rolü benimseyen kişiden nefret edileceğini ve gruptan atılacağını varsayabilir. $\mathrm{Bu}$ rolün verilmesi konusunda literatürde bazı öneriler bulunmaktadır. Şeytanın avukatı rolüne atanan bireye rolü açık ve net bir şekilde verilmeli ve kişinin akıllıca ve ikna edici bir şekilde halihazırdaki düşüncelere alternatif getirmesi beklenmelidir (Janis, 1972). Burada önemli olan bir nokta, diğer grup üyelerinin bu role atanan grup üyesine ilişkin tutumunun olumlu olmasıdır (Coşkun, 2013a,b). Grup liderinin bu rolü ataması ve grup üyelerine tanıtması bu rolü oynayan kişiye karşı olumlu tutum gelişimine katkıda bulunacaktır.

Literatürde grup içinde şeytanın avukatı rolünün daha etkili olması için bazı öneriler araştırmacılar tarafindan sunulmaktadır (Schweiger, Sandberg ve Ragan, 1986). Schweiger, Sandberg ve Ragan (1986) grupların iki alt gruba bölünerek bir alt gruba şeytanın avukatı rolünün atanması ile oturumun başlamasını önermektedir. Şeytanın avukatının olmadığı grup probleme yönelik çözüm önerileri üretmektedir ve şeytanın avukatı bu esnada probleme yönelik eleştirilebilecek 
ya da yenilikçi olabilecek olan kendi düşüncelerini de hazırlamaktadır. İlk grubun yazılı önerilerini sunmasının ardından şeytanın avukatı eleştiriye veya konuşmaya başlamakta ve alternatif tavsiye içeren düşüncelerini sunmaktadır. Sonrasında şeytanın avukatı olmayan alt grup tavsiye ve önerilerini sunmaktadır ve şeytanın avukatı bu durumlara da eleştiri getirmektedir. Oturumun en sonunda, oturumun aşamalarındaki en son varsayımlar ve öneriler dâhilinde nihai öneriler yazılmaktadır. Yazılan bu son öneriler oylanmakta ve bu şekilde karar verme gerçekleştirilmektedir.

\section{Grup Düşünmeyi Önleme Tekniği Olan Şeytanın Avukatı Konu- sunda Yapılan Araştırmalar}

Schwenk (1990) şeytanın avukatı ile ilgili yaptı̆̆ı meta analiz çalışmasında, şeytanın avukatına maruz kalan bireylerin şeytanın avukatına maruz kalmayanlara göre daha iyi kararlar verdiklerini savunmuştur. Ancak son zamanlarda yapılan araştırmalar şeytanın avukatı rolünü diğer tekniklerle karşılaştırmakta ve bu şekilde tekniğin ne kadar etkili olduğunu göstermeye çalışmaktadır.

\section{Şeytanın Avukatı Rolü ile Muhalif Olmanın Karşılaştırılması}

Şeytanın avukatı rolünün karşılaştırıldığı tekniklerden biri grup içinde muhalefet yapan gruplardır. Muhalefet yapan gruplardan istenen şey grupta ortaya çıkan düşüncelere muhalif olmadır. Meselâ, Nemeth, Connell, Rogers ve Brown (2001) ve Nemeth, Brown ve Rogers (2001) tarafından yapılan araştırmalarda, özgün muhalefet yapılmasına (yeni karş1 düşünceler oluşturmaya) yönelik yönerge verilen gruplar ile şeytanın avukatı rolünü oynayan bireyin olduğu gruplar düşünce sayısı 
ve niteliği açısından karşılaştırılmıştır. $\mathrm{Bu}$ araştırmanın sonucunda, muhalefet yapan grupların şeytanın avukatı olan gruplara göre konun bütün yönlerini taradıkları ve böylece daha ıraksak (farklı) düşünceler ürettikleri ortaya çıkmıştır. Araştırmacılar, şeytanın avukatı rolünün etkin olduğu gruplarda konunun her yönü ile tartışılmadığına dikkati çekmişlerdir. Araştırmacılar, yaptıkları ilk çalışma sonucunda şeytanın avukatı yönteminin özgün muhalefet yöntemi kadar etkin olmasa da etkin bir yöntem olduğunu vurgulamaktadır.

Şeytanın avukatı tekniğine yönelik, Schulz-Hardt, Jochims ve Frey (2002) tarafından yapılan çalışmada şeytanın avukatı yöntemine göre oluşturulan yapay bir muhalefet ortamına oranla gerçek muhalefet ortamının grup karar verme sürecinde daha verimli olduğu sonucuna ulaşmışlardır. Aynı zamanda araştırmacılar tarafından şeytanın avukatı gibi bir işlem ile grup karar verme sürecinde bir çatışma durumu oluşturulduğunda, üyelerin görevle ilgili daha verimli bir şekilde tartışmaya alışık hâle gelebileceği ve grubun kendi karar verme sürecine yönelik bir kültür oluşturabileceği önerilmiştir. Bunun yanı sıra şeytanın avukatı tekniğinin grup içerisinde yarattığı çatışma ortamının, olumsuz etkiye neden olabileceğini de ele alan çalışmalar mevcuttur. Grup içerisindeki çatışma ortamının, diğer grup üyeleri tarafından aşağılama ve tartışma olarak algılandığında grup üyeleri arasındaki iletişim ağının kopabileceği ve grup ortamında oluşan güvensizlik nedeniyle grup karar verme sürecine şeytanın avukatı yönteminin olumsuz bir temel oluşturabileceği de literatürde rapor edilmiştir (Schweiger, Sandberg ve Ragan, 1986). 
Şeytanın avukatı ve özgün muhalefet teknikleri özellikle endüstriyel sektörde de iş odaklı grup kararlarında şeytanın avukatı tekniğinin hassas yönelimli fikirleri bastırarak grup karar verme sürecini olumsuz yönde etkilediğini ve bu nedenle çatışmacı olmayan rol oynama tekniklerinin daha olumlu sonuçlara yol açabileceğini savunmuşlardır (Kelley ve Littman, 2005).

\section{Şeytanın Avukatı Rolü ile Diyalektik Sorgulama Tekniğinin ve}

\section{Diğerlerinin Karşılaştırılması}

Grup düşünmenin azaltılması için önerilen şeytanın avukatı tekniğine bir başka seçenek diyalektik sorgulama tekniğidir. Diyalektik sorgulama tekniği, grup karar verme esnasında konu hakkındaki tez ve antitezlere -yani birbiri ile zit durumları keşfederek- odaklanmayı içermektedir (Schweiger, Sandberg ve Ragan, 1986; Schwenk, 1983; Schwenk 1990). Bu teknik Antik Yunan'da Eflatun (Plato) tarafından geliştirilen tez ve antiteze dayalı bir teknikle gerçeği ortaya çıkarmaya dayanmaktadır (Brooke, 2012; Recco, 2012). Amerika Birleşik Devletleri'nde ve bazı ülkelerde adlî sistemde suçluyu veya suçsuzluğu belirlemek için zıt görüşlere önem verilmektedir (Calvi, 2012). Temel olarak bu teknik iki zıt görüş hakkında tartışma veya sorgulamayı içermektedir (Katzenstein, 1996).

Diyalektik sorgulama tekniği, grupların iki alt gruba ayrılması ve sorun ya da problem durum hakkında öneri ve karşııt öneri geliştirilmesine dayalı bir tekniktir. Şeytanın avukatı ve diyalektik sorgulama yöntemleri farklı yapılandırılsa da her iki yöntem de gruplarda iki tarafın tartışmasını içeren ve genel olarak kişileri bilişsel çatışmaya teş- 
vik eden yöntemlerdir. Bu çatışmalarda grup açık görüşlü olmadığında, grup karar vericilerin bilişsel çatışma yerine duygusal çatışma yaşaması muhtemeldir ve bu durum grup karar verme performansı için olumsuz bir durum olarak rapor edilmiştir (Amason ve Sapienza, 1997). Ayrıca şeytanın avukatı rolünün grup içinde olumsuz olarak algılanmasından dolayı karşıt plânlar geliştirme yöntemine dayalı bir teknik olan diyalektik sorgulama tekniği literatürde bir başka seçenek olarak önerilmektedir (Mason, 1967).

Şeytanın avukatı rolünün ne kadar etkili olduğunu belirlemek için, literatürde bu tekniği diyalektik sorgulama tekniği ve diğer tekniklerle karşılaştıran çalışmalar bulunmaktadır (Cosier, 1978, 1980; Cosier ve Alpin, 1980). Yapılan bu çalışmalar şeytanın avukatı tekniği ve diyalektik sorgulama tekniklerinin diğer tekniklere göre (örn; uzlaşma, uzman gruplar) grup karar verme aşamasında daha kaliteli kararları sağladığından dolayı daha verimli olduğu bulgusuna ulaşılmıştır. Diğer yandan diyalektik sorgulama ve şeytanın avukatı teknikleri karşılaştırıldığında ulaşılan sonuçlarda grup karar verme konusunda her iki teknik arasında anlamlı bir fark olmadığı sonucuna ulaşılmıştır (Cosier, 1978, 1980; Schwenk ve Cosier, 1980; Schwenk ve Valacich, 1994). Bu bulguların yanı sıra Schwenk ve Cosier (1980) şeytanın avukatı tekniğinin diyalektik sorgulama tekniğine göre daha etkin olduğunu; çünkü doğru kararlardan birçoğunun tez ve antitez arasında yer alabileceğini savunmuşlardır. Yani şeytanın avukatı tekniği eleştiri, olumsuz ve yıkıcı olmak yerine yapıcı ve yenilik getirici olmasına özen gösterilerek yapıldığında, daha etkili sonuç doğurmaktadır (Valacich ve 
Schwenk, 1995a). Araştırmacılar bu bağlamda negatif eleştirinin daha düşük kaliteli çözüm önerilerini ortaya çıkardığı bulgusunu rapor etmişlerdir (Valacich ve Schwenk, 1995a).

Şeytanın avukatı, diyalektik sorgulama ve uzlaşma (kontrol grubu) tekniklerinin grup karar verme performansına etkisinin incelendiği bir çalışmada (Quaddus, Tung, Chin, Seow ve Tan, 1998) genel olarak kişiler arası çatışmaların üretilmesinde ve üretkenlik bağlamında söz konusu üç teknik arasında anlamlı bir fark olmadığı sonucuna ulaşılmıştır. Ancak sorun bazlı çatışmalar için sonuçların farklılaştı̆̆ 1 ve görev türünün etkisinin önemli olduğu bulgusu rapor edilmiştir. Çalışmada; görev türleri, kaynak tahsis edilmesi ve stratejik plânlama olarak ikiye ayrılmıştır. Çalışma sonuçlarında, kaynak tahsisi görevinde, diyalektik sorgulama tekniği diğerlerine göre daha iyi bir grup karar verme performansı sağlamaktadır. Öte yandan, stratejik planlama görevinde ise şeytanın avukatı yönteminin diğer iki tekniğe göre grup karar verme performansını arttırdığı bulgusuna ulaşılmıştır. Araştırma sonucundan yapısal olarak farklı görev türlerinde bu iki benzer tekniğin farklı sonuçlar ortaya çıkardığı ve özellikle şeytanın avukatı yönteminin bilişsel temelli problemlerde daha etkin olduğu varsayılmaktadır. Diğer yandan çatışma yönetimi stratejilerine bakıldığında diyalektik sorgulama ve şeytanın avukatı tekniklerinde bu tür stratejilerin, uzlaşma tekniğine göre daha az kullanıldığı bulgusuna ulaşılmıştır.

Schweiger, Sandberg ve Ragan (1986), yapılandırılmamış bir teknik olan uzlaşma tekniği ile şeytanın avukatı tekniğinin karşılaştırmasını içeren çalışmalarında, şeytanın avukatı yönteminin yüksek 
kaliteli kararlar ve tavsiyeler sağladığı bulgusuna ulaşılmıştır. Çalışmada katılımcılar örnek olaylar konusunda karar vermek için dört gruba ayrılmışlardır. Gruplara kendilerine atanan teknikler bağlamında sorunlu ilaç depoları için öneriler geliştirme görevi verilmiştir. Gruplar iki yargıcı tarafından üç standartta değerlendirilmiştir;

1. Önerilen varsayımların sayısı,

2. Varsayımların geçerliliği,

3. Varsayımların önemi.

Çalışma sonuçlarında; şeytanın avukatı ve diyalektik sorgulama tekniğinin, uzlaşma tekniğine göre önemli ölçüde daha yüksek kaliteli ve geçerliliği yüksek olan öneriler sağladığı bulgusuna ulaşılmıştır.

Cosier ve Aplin' in (1980), diyalektik sorgulama, şeytanın avukatı ve uzman atama tekniklerini karşılaştırdıkları çalışmalarında, katılımc1lar dört çalışma grubuna seçkisiz veya rastgele atama yolu ile atanmışlardır. Çalışmada katılımcılara plânlama müdürü olduklarına dâir bir rol verilmiş ve her bir çalışma grubu operasyonel olarak tanımlanmıştır. Diyalektik sorgulama tekniğinde iki farklı danışmanlık grubu rapor oluşturmuş ve raporda plân ve karşı plân oluşturmuştur. Şeytanın avukatı tekniğinde aynı anda iki rapor oluşturulmuş ve raporda, plân ve plânın eleştirisi bulunmaktadır. Uzman atama tekniğinde ise bir plânlama uzmanının hazırladığı rapor verilmiştir. Kontrol koşulunda ise raporun nasıl geliştirileceğine dâir sadece yönerge verilmiştir. İki yargıcı tarafından 6 kriter çerçevesinde değerlendirilen plânlar sonucunda şeytanın avukatı tekniğinin uygulandığ 1 koşulda diğer teknikle- 
rin uygulandığı koşullara göre daha üstün olduğu sonucuna ulaşılmıştır.

Valacich ve Schwenk (1995a), şeytanın avukatı tekniğini yüz yüze ve bilgisayar ortamında test ettikleri çalışmalarında, her iki tekniğin diğer tekniklere göre daha kaliteli ve alternatif çözümler sağladığı bulgusuna ulaşmışlardır. Murrell, Stewart ve Engel (1993) bu bulguya paralel olarak yaptıkları çalışmalarında, üç farklı görev türü (katkılı, ayrıştırıcı, birleştirici) için şeytanın avukatı yöntemini uzlaşma yöntemi ile karşılaştırmışlardır. Çalışmada; katkılı görevlerde, grup performansı bireysel çabaların toplamı ile tespit edilmektedir. Ayrıştırıcı görevde, grupta bulunan bireylerin sunduğu çözümlerden en uygun çözüm seçilmektedir. Birleştirici görevde ise görevde başarılı olabilmek için bütün grup üyeleri arasında koordinasyon olmalı ve her üye farklı bir katkı yapmalıdır. Bu görevler için karar verme tekniklerinin karşılaştırıldığı çalışmada, özellikle ayrıştırıcı nitelikteki görevler için şeytanın avukatı yönteminin grup karar verme için en etkili yöntem olduğunu savunurken, birleştirici görevler üzerinde yöntemin bir etkisinin olmadığı, katkılı görevlerde ise grup karar vermeyi geciktirdiği bulgusu rapor edilmiştir. Ayrıca ilgili çalışmada, uzlaşma tekniğini kullanan grupların şeytanın avukatı tekniğini kullanan gruplara göre grup atmosferini daha olumlu olarak nitelendirdiği sonucuna da ulaşılmıştır. Şeytanın avukatı yöntemindeki eleştirilerin grup içindeki olumlu ya da 1lımlı atmosferin önüne geçtiği varsayılabilmektedir. $\mathrm{Bu}$ bulgu ile bağlantılı olarak Schweiger, Sandberg ve Ragan (1986) uzlaşma grupları gelecekte aynı grupla tekrar çalışma konusunda daha istekli oldukları sonucuna ulaşmışlardır. Ayrıca grup içinde sosyal uyumun, 
katılımcılar tarafından en fazla uzlaşma gruplarında hissedilmesinin yanı sıra grup içinde en az olumlu duyguların hissedildiği tekniğin şeytanın avukatı tekniği olduğu bulgusu da mevcuttur (Priem ve Price, 1991). Bu bulgu bağlamında şeytanın avukatı tekniğinin karar verme kalitesini arttırdığ1; ancak grup doyumunu azalttığı varsayılabilir. Şeytanın avukatı yönteminin gerçek sorunlara çözüm oluşturmak için 1lımlı bir çatışma ortamı eleştiri ve yaratıcılıkla birleştiren bir teknik olduğu ve teknik bu yönde kullanıldığında etkili olabileceği savunulmaktadır (Hartwig, 2010).

Grup karar verme oturumları esnasında; bir üye, mümkün olduğunca her konu hakkında alternatif düşünceler getiren bir role atanabilir (Schweiger ve Finger, 1984). Şeytanın avukatı rolünün bir türevi olarak “çoklu savunma" yöntemi de önerilmektedir (George, 1972). Bu yöntem, kuruluşun içinden ya da dişından atanacak birçok eleştirmenin grup karar verme süreçlerine katılımını içerir ve grup karar verme sürecindeki her bir grup kendi şeytanın avukatı tarafından savunulabilmektedir. George (1972), “çoklu savunma”nın tekli şeytanın avukatının olduğu koşula göre daha etkin olduğunu; çünkü daha fazla şeytanın avukatının daha fazla fikre yol açacağını savunmaktadır. Bu gruplarda şeytanın avukatları diğer üyelerden maksimum düzeyde farklı düşünmelidir.

Grup karar verme sürecinin başlangıç aşamalarında, çatışma mevcut ise ve gruptaki her üye kendi düşüncesini savunuyorsa, şeytanın avukatı karar verme süreci boyunca aktif olmalıdır (Janis, 1972). Şeytanın avukatının rolünü üstlenen bireye karşı olumsuz bir yargı 
oluşmasına karşın, şeytanının avukatı rolünün grup içinde rotasyon ile değişmesi önerilmektedir (Kreitner ve Kinicki, 2010). Birçok kuruluş, şeytanın avukatı rolünü çeşitli şekillerde kullanmaktadır (Ivancevich, Konopaske ve Matteson, 2011). Ayrıca yapılan çalışmalar, lider biçimlerinin katılımcı ve yönlendirici olmasının yanı sıra, şeytanın avukatı rolünü üstlenmesi önerisini getirmektedir (Park, 1990). Şeytanın avukatı tekniğinin, grup karar verme bağlamında, uzman desteğine göre daha iyi sonuçlar verdiği bulgusu da literatürde mevcuttur (Schwenk ve Cosier, 1980). Schwenk (1990), grup karar verme kalitesinin de gruplara şeytanın avukatının katılımı ile arttığ bulgusuna ulaşmiştır.

\section{Tartışma}

Sonuç olarak şeytanın avukatı rolünün grup içinde iyi plânlanması gerekmektedir. Şeytanın avukatı grup içinde güvenilir biri olarak algılanmadığında ve grup içinde yapıcı değil çatışmacı bir kültür oluştuğunda şeytanın avukatı rolü oynayan kişinin sunduğu görüşler dikkate alınmamaktadır. Ayrıca, yapılan araştırmalarda şeytanın avukatı rolünü oynayan bir kişi gruplarda bulunmaktadır. Öte yandan, muhalif olma durumu söz konusu araştırmalarda bütün grup üyelerinden istenmektedir. $\mathrm{Bu}$ tür işlem araştırmalarda karıştırıcı rol oynamaktadır. Grup içinde bu rolü oynayan kişilerin sayısını artırmak yeni düşüncelerin diğer grup üyeleri tarafından kabul edilmesini ve daha fazla dikkate alınmasını kolaylaştıracaktır. Gelecekte yapılacak araştırmalarda grup içinde şeytanın avukatı rolünü oynayan kişilerin iki veya daha fazla olduğu grupları bütün üyeleri muhalif olan gruplarla 
karşılaştırmak uygun bir yaklaşım olacaktır.

Şeytanın avukatı tekniğini diyalektik teknikle karşılaştırıldığı araştırmalar incelendiğinde, şeytanın avukatının tekniğinin çoğunlukla daha kaliteli kararlara yol açtığı gözlenmektedir. Bununla birlikte bu tekniğin etkili olması için bu rolü üstlenen grup üyelerinin eleştiri, olumsuz ve yıkıcı olmak yerine yapıcı ve yenilik getirmeye özen göstermesi gerekmektedir (Valacich ve Schwenk, 1995a). Aksi takdirde negatif eleştiri daha düşük kaliteli çözüm önerilerini ortaya çıkaracaktır (Valacich ve Schwenk, 1995a). Bu tekniği kullanmada dikkate alınacak önemli bir konu gruplara verilen görevin veya işin türüdür. Plânlama görevlerinde bu teknik daha kaliteli kararların ortaya çıkmasına yol açmaktadır (Quaddus ve ark., 1998). Görevin grup üyelerine dağıtımı söz konusu olduğunda diyalektik sorgulama daha fazla avantaj sağlamaktadır. Ayrıca, rapor oluşturma ve rol vermenin olduğu işlerde bu teknik daha etkili görünmektedir (Cosier ve Aplin, 1980). Özellikle grup içinde en uygun çözümü bulma söz konusu olduğunda şeytanın avukatı tekniği, diğerlerine göre daha fazla fayda sağlamaktadır (Murrell, Stewart ve Engel, 1993). Şeytanın avukatı rolünün bir rotasyonla grup üyelerine verilmesi ve bu rotasyonu liderin belirlemesi bu rolü üstlenen kişilerin kabul edilmesini artıracaktır. Burada vurgulanması gereken önemli bir konu, bu rolü üstelenen kişinin bu rolü grubun faydasına yönelik yaptığının anlaşılması veya kavranabilmesidir. Rolü üstlenen kişinin uzman veya lider olarak algılandığı durumlarda öneriler daha fazla kabul edilecek ve bu durum grubu grup düşünme sendromundan kurtaracaktır. 
Şeytanın rolünün kabul edilmesinde sosyal veya ortak kimliğin incelenmesi önemli bir konudur (Coşkun, 2013b). Şeytanın rolü avukatı rolüne sahip olan kişinin, grup içinden biri olarak algılanması durumunda önerileri daha fazla kabul edilecektir. Öte yandan, bu kişinin dış bir grubun ve hatta öteki bir grubun üyesi olarak görülmesi durumu değiştirecektir. Böyle bir durumda bu rolü olan kişinin önerileri bu algılamadan dolayı kabul edilmemesi olasılığg yüksektir. Gelecekte yapılacak araştırmaların bu konuyu aydınlatılması gerekmektedir. Grup düşünmeyi azaltmanın yollarından biri gruplara beyin firtınası yaptırmaktır. Bu öneri henüz literatürde test edilmemesine rağmen, farklı ve çok sayıda düşüncelerin sansürlenmeden ortaya atıldığı beyin fırtınasının oturum öncesinde uygulanması bu tür düşünmeyi azaltabilir. Gelecekte araştırmaların bu konuyu aydınlatması, alana önemli katk1 getirecektir.

\section{Kaynakça}

Aldag, R. J. ve Fuller, S. R. (1993). Beyond fiasco: A reappraisal of the groupthink phemenon and a new model of group decision processes. Psychological Bulletin, 113(3), 534.

Amason, A. C. ve Sapienza, H. (1997). The effects of top management team size and interaction norms on cognitive and affective conflict. Journal of Management, 23, 496-516.

Asch S. E. (1952b). Social psychology. Englewood Cliffs, NJ: Prentice-Hall.

Brooke, C. (2012). Ideas of education: Philosophical and political perspectives from Plato to the nineteenth century. New York, NY: Routledge. 
Burnstein, E. ve Vinokur, A. (1973). Testing two classes of theories about group-induced shifts in individual choice. Journal of Experimental Social Psychology, 9, 123- 137.

Calvi, J. V. (2012). American law and legal systems. New York, NY: Longman.

Cosier, R. A. (1978). The effects of three potential aids for making strategic decision on prediction accurary. Organizational Behaviour and Human Performance, 22, 295-306.

Cosier, R. A. (1980). Inquiry method, goal difficulty, and context effects on performance. Decision Sciences, 11, 1-16.

Cosier, R. A. ve Aplin, J. C. (1980). A critical view of dialectical inquiry as a tool in strategic planning. Strategic Management Journal, 1, 343-356.

Cosier, R. A. ve Schwenk, C. R. (1990). Agreement and thinking alike: Ingredients for poor decisions. Academy of Management Executive, 4, 69-74.

Coşkun, H. (2013a). Davranış bilimlerine giriş. M. Paksoy, (Ed.), Inanç, tutum, davranış içinde (103-118). İstanbul: Lisans Yayıncılık.

Coşkun, H. (2013b). Psikolojiye giriş. H. Coşkun ve N. Ş. Özabacı, (Ed.), Sosyal psikoloji içinde (495-520). İstanbul: Lisans Yayıncilik.

De Dreu, C. K. W. ve Van de Vliert, E. (Ed.). (1997). Using conflict in organizations. London: Sage.

George, A. L. (1972). The Case for multiple advocacy in making foreign policy. American Political Science Review 66(3), 751-78. 
Hartwig, R. T. (2010). Facilitating problem solving: A Case study using the devil's advocacy technique. A Research \& Applications Journal, 10, 3-31.

Ivancevich, J. M., Konopaske, R. ve Matteson, M. T. (2011). Organizational behavior and management. New York, NY: McGraw-Hill.

Janis, I. L. (1972). Victims of groupthink. New York: Houghton Mifflin.

Janis, I. L. (1982). Groupthink: Psychological studies of policy decisions and fiascoes. (2. bask1). New York: Houghton Mifflin.

Katzenstein, G. (1996). The debate on structured debate: Toward a unified theory. Organizational Behavior and Human Decision Processes, 66(3), 316-332.

Kelley, T. ve Littman, J. (2005). The Ten faces of innovation: IDEO's strategies for beating the devil's advocate \& driving creativity throughout your organisation. New York: Currency Doubleday.

Kreitner, R. ve Kinicki, A. (2010). Organizational behavior (9. bask1). Irwin: The McGraw-Hill Companies.

Mason, R. O. (1967). A dialectical approach to strategic planning. Managment Science, 15(8), B403-B414.

Mason, R. O. ve Mitroff, I. I. (1981). Challenging strategic planning assumptions: Theory, cases and techniques. NY: Wiley.

Murrell, A. J., Stewart, A. C. ve Engel, B. T. (1993). Consensus versus devil's advocacy: The influence of decision process and task structure on strategic decision making. Journal of Business Communication, 30, 399-414. 
Myers, D. G. ve Lamm, H. (1976). The group polarization phenomenon. Psychological Bulletin, 83, 602-627.

Nemeth, C., Brown, K. ve Rogers, J. (2001). Devil's advocate versus authentic dissent: Stimulating quantity and quality. European Journal of Social Psychology, 31, 707-720

Nemeth, C., Connell, J., Brown, K. ve Rogers, J. (2001). Improving decision making by means of dissent. Journal of Applied Psychology, 3(1), 48-58.

Park, W. (1990). A review of research on groupthink. Journal of behavioral Decision Making, 3, p. 232.

Quaddus, M. A., Tung, L. L., Chin, L., Seow, P. P., ve Tan, G. C. (1998). Non-networked group decision support systems: effects of devil's advocacy and dialectical inquiry. Proceedings of the Thirty-First Hawaii International Conference on Systems Sciences, 1, 38-47.

Recco, G. (2012). Plato's laws: Force and truth in politics. Bloomington, Indiana: Indiana University Press.

Robbins, S. P. (1997). Essentials of organizational behavior. New Jersey: Prentice Hall.

Schulz-Hardt, S., Jochims, M. ve Frey, D. (2002). Productive conflict in group decision making: Genuine and contrived dissent as strategies to counteract biased information seeking. Organizational Behavior and Human Decision Processes, 88, 563-586.

Schweiger, D. M. ve Finger, P. A. (1984). The comparative effectiveness of dialectical inquiry and devil's advocacy: The impact of task biases on previous research findings. Strategic 
Management Journal, 5, 335-350.

Schweiger, D. M., Sandberg, W. R. ve Ragan, J. W. (1986). Group approaches for improving strategic decision making: A comparative analysis of dialectical inquiry, devil's advocacy, and consensus. Academy of Management Journal, 29(1), 51-71.

Schwenk, C. R. (1990). Effects of devil's advocacy and dialectical inquiry on decision making: A meta-analysis. Organizational Behavior and Human Decision Processes, 47, 161-176.

Schwenk, C. R., (1983). Laboratory Research On Illstructured Decision Aids: The Case of Dialectical Inquiry, Decision Sciences, Vol 14, 14-144.

Schwenk, C. R. ve Cosier, R. A. (1980). Effects of the expert, devil's advocate, and dialectical inquiry methods on prediction performance. Organizational Behavior and Human Performance, 26, 409-424.

Schwenk, C. ve Valacich, J. S. (1994). Effects of devil's advocacy and dialectical inquiry on individuals versus groups. Organizational Behavior and Human Decision Processes, 59, 210-222.

Valacich, J. S. ve Schwenk, C. (1995a). Devil's advocacy and dialectical inquiry effects on face-to-face and computermediated group decision making. Organizational Behavior and Human Decision Processes, 63, 158-173.

Valacich, J. S. ve Schwenk, C. (1995b). Structuring conflict in individual, face-to-face, and computer-mediated group decision making: Carping versus objective devil's advocacy. Decision Sciences, 26, 369-392. 